\title{
Discursos do Professor de Matemática e suas Implicações na Compreensão dos Alunos
}

\section{Mathematics Teacher's Speech and its Implications in Student's Understanding}

\author{
Pedro Lucio Barboza* \\ Rômulo Marinho do Rego** \\ Jonei Cerqueira Barbosa***
}

\begin{abstract}
Resumo
O objetivo deste artigo é identificar e analisar situações de interações discursivas na sala de aula de matemática que podem favorecer a compreensão do discurso do professor pelo aluno. Para analisar as situações de interações discursivas, utilizamos elementos da teoria da linguagem de Bakhtin, em especial o conceito de compreensão, e apresentamos o conceito de compreensão intermediária. Os dados utilizados em uma abordagem qualitativa foram obtidos por meio de observação, registrados em videogravação das aulas. Os resultados mostram três situações de interações discursivas que favorecem a compreensão do discurso da professora pelos alunos: 1) o discurso se refere a situações do dia-a-dia; 2) quando a professora discursa, relativizando o rigor da linguagem matemática; 3) a professora realiza discursos fazendo comparações entre objetos matemáticos.
\end{abstract}

Palavras-chave: Discurso do Professor. Interações Discursivas. Compreensão dos Alunos.

\footnotetext{
" Doutor em Ensino, Filosofia e História das Ciências pela Universidade Federal da Bahia (UFBA). Professor da Universidade Estadual da Paraíba (UEPB), Campina Grande, PB, Brasil. Endereço para correspondência: Rua Tabelião Severino de Lacerda, 40, Bairro Catolé, CEP: 58410-528, Campina Grande, PB, Brasil. E-mail: plbcg@ yahoo.com.br.

*** Doutor em Educação pela Universidade Federal do Rio Grande do Norte (UFRN). Professor Pesquisador do Programa de Pós-Graduação em Ensino de Ciências e Matemática da Universidade Estadual da Paraíba (UEPB), Campina Grande, PB, Brasil. Endereço para correspondência: Rua Baraúnas, 351, bairro Universitário, CEP: 58429-500, Campina Grande, PB, Brasil. E-mail: romulomate@gmail.com.

**** Doutor em Educação Matemática pela Universidade Estadual Paulista (UNESP). Professor Adjunto do Departamento II da Faculdade de Educação da Universidade Federal da Bahia (UFBA), Salvador, BA, Brasil. Endereço para correspondência: Avenida Reitor Miguel Calmon s/n, Campus Canela, CEP: 40110-100, Salvador, BA, Brasil.E-mail: jonei.cerqueira@ufba.br.
} 


\begin{abstract}
The primary objective of this article is to analyze situations with discursive interactions in math classrooms, which may prompt student's understanding of teacher's speech. To analyze the situations with discursive interactions, this study used elements from Bakhtin's theory of language, mainly its concept of comprehension, and introduces the new concept of intermediate comprehension. The data used in a qualitative approach were collected from class observation through video-recorded lessons. The results showed three situations with discursive interactions that contribute to understanding of the school teacher's speech: 1) speech referring to everyday situations; 2) the teacher's speech math in a less rigorous way 3 ) teacher comparing different mathematical objects.
\end{abstract}

Keywords: Teacher's Speech. Discursive Interactions. Student’s Understanding.

\title{
1 Introdução
}

Este artigo busca identificar e analisar situações de interações discursivas na sala de aula de matemática que podem favorecer a compreensão do discurso do professor pelos alunos. Para isto, focalizaremos as interações ocorridas entre professor e alunos ou entre os próprios alunos para levantar evidências empíricas para elaborarmos uma compreensão para o propósito delineado.

No presente estudo, consideramos as situações de interações discursivas na sala de aula de matemática como uma prática social, na qual se envolvem, pelo menos, dois interlocutores. Uma interação discursiva é o contato verbal, gestual ou por meio de imagens entre, ao menos, dois sujeitos.

Sobre o discurso, Bakhtin o expressa assim: "A palavra indefinida riétch ('fala, [discurso]'), que pode designar linguagem, processo de discurso, ou seja, o falar, um enunciado particular ou uma série indefinidamente longa de enunciados e um determinado gênero discursivo" (BAKHTIN, 2003, p. 274). No presente estudo, consideramos discurso como ações que se manifestam de formas variadas, por meio de realizações gestuais, escritas ou orais da linguagem ${ }^{1}$, em particular, as ações que professores e alunos realizam no ambiente da sala de aula. Assim, entendemos que a palavra discurso abrange as mais diversas formas de manifestação da linguagem e da comunicação verbal.

${ }^{1}$ Conforme afirma Duval (D’AMORE, 2007) há pelo menos quatro diferentes maneiras de entender a palavra linguagem: 1) como língua; 2) como diferentes formas de discurso; 3) como função geral da comunicação; 4) como uso de um código. Linguagem é um fenômeno colocado por Bakhtin nos seguintes termos: "[...] para observar o fenômeno da linguagem, é preciso situar os sujeitos emissor e receptor do som, no meio social. Com efeito, é indispensável que o locutor e o ouvinte pertençam à mesma comunidade linguística, a uma sociedade claramente organizada" (BAKHTIN, 2006, p.72). 
Neste trabalho, consideramos a perspectiva de Bakhtin (2006) sobre conceituar compreensão. Para ele, compreender o discurso do outro é ter uma orientação em relação ao que foi dito, encontrar para o enunciado ${ }^{2}$ um lugar adequado no contexto em que está sendo produzido.

Compreender a enunciação de outrem significa orientar-se em relação a ela, encontrar o seu lugar adequado no contexto correspondente. A cada palavra da enunciação que estamos em processo de compreender, fazemos corresponder uma série de palavras nossas, formando uma réplica" (BAKHTIN, 2006, p. 137).

A compreensão não é um mero processo passivo de decodificação da linguagem, afirma Bakhtin.

Para Bakhtin (2006, 2003), a compreensão se acha na base da resposta, ou seja, na interação verbal. Ele afirma ser impossível delimitar, de modo estrito, o ato de compreensão e a resposta, porque todo ato de compreensão é uma resposta, na medida em que ele introduz o objeto da compreensão num novo contexto - o contexto potencial da resposta.

Nessa perspectiva, o ouvinte, a cada palavra da enunciação que está buscando compreender formula um conjunto de palavras próprias. A compreensão é uma forma de diálogo ${ }^{3}$, diz Bakhtin (2006), e ainda acrescenta que compreender é opor à palavra do locutor uma contra-palavra. Não significa dizer que compreender é se opor a determinado discurso, mas usar o discurso anterior para formular um discurso resposta.

Na perspectiva de Bakhtin (2006), a compreensão se encontra na base da resposta. Em uma das passagens de seus textos, Bakhtin prevê a possibilidade de ocorrer em diversos níveis de compreensão, quando ele se refere à relação entre a quantidade e qualidade das palavras e a compreensão, na afirmação, "quanto mais numerosas e substanciais forem, mais profunda e real é a nossa compreensão" (BAKHTIN, 2006, p. 137). Aqui, o autor considera a possibilidade de a compreensão poder ocorrer em níveis variados de profundidade.

Já em outras referências, em seus textos, haveria apenas duas possibilidades: a compreensão passiva ou a compreensão ativa plena. $\mathrm{Na}$

\footnotetext{
${ }^{2} \mathrm{O}$ enunciado é descrito em Bakhtin (2003) como sendo a unidade real da comunicação que permite "compreender de modo mais correto também a natureza das unidades da língua" (BAKHTIN, 2003, p. 269). Neste estudo, empregamos os termos enunciado e enunciação com o mesmo significado.

${ }^{3}$ Flores et al. (2009) apresenta o diálogo em Bakhtin do seguinte modo: "propriedade constitutiva de todo discurso que pressupõe comunicação com outros discursos e o discurso do outro, independentemente da estrutura dos enunciados" (FLORES et al., 2009, p.81).
} 
passagem a seguir, está expresso o que ele entende por compreensão ativa plena ou compreensão ativa ou compreensão plena, "toda compreensão plena real é ativamente responsiva e não é senão uma fase inicial preparatória da resposta (seja qual for a forma em que ela se dê)" (BAKHTIN, 2003, p. 272). Então, em qualquer forma que ela se dê a compreensão é uma compreensão ativa plena, para Bakhtin.

A compreensão passiva ele propõe assim: "O tipo de compreensão, que exclui de antemão qualquer resposta, nada tem a ver com a compreensão da linguagem. Essa última confunde-se com uma tomada de posição ativa a propósito do que é dito e compreendido" (BAKHTIN, 2006, p. 102). O tipo de compreensão em que não há resposta do interlocutor ao enunciado é uma compreensão passiva, onde não ocorre a compreensão da linguagem.

Segundo Bakhtin (2006), a compreensão passiva caracteriza-se apenas pela leitura do que está escrito: "a compreensão passiva caracteriza-se justamente por uma nítida percepção do componente do signo linguístico" (BAKHTIN, 2006, p. 102). O autor ainda acrescenta sobre a compreensão passiva: "uma compreensão totalmente passiva, que não comporta o esboço de uma resposta, como seria exigido de qualquer espécie autêntica de compreensão" (BAKHTIN, 2006, p. 101). Na compreensão passiva ocorre apenas a identificação do código linguístico.

Dessa maneira, a compreensão passiva é caracterizada por não apresentar nenhum tipo de resposta; enquanto a compreensão ativa, a compreensão plena, ou compreensão ativamente responsiva comporta, para Bakhtin, qualquer tipo de resposta.

Sendo tomados para analisar como os alunos compreendem o discurso do professor de matemática, os conceitos formulados por Bakhtin (2003, 2006) sobre compreensão ativa plena e compreensão passiva, possibilitam a apresentação da noção teórica de compreensão intermediária como uma ferramenta para analisar como os alunos compreendem o discurso do professor na sala de aula.

Do modo como Bakhtin propõe o conceito de compreensão ativa plena, esse parece-nos amplo. Compreendemos que existem diversas formas de compreensão e, ao mesmo tempo, não consideramos possível estabelecer uma escala de níveis de compreensão, então, para esses níveis de compreensão situados entre a compreensão passiva e a compreensão ativa plena, estamos apresentando a noção teórica de compreensão intermediária, com capacidade para capturar aquela compreensão que se situa entre a ativa e a passiva.

Na formulação de Bakhtin (2003, 2006), a compreensão ocorre de maneira plena (compreensão ativa), ou então, quando há apenas a compreensão 
do signo linguístico (compreensão passiva). Assim, consideramos limitado o modo como ele analisa a compreensão de modo que também sirva ao propósito de capturar como os alunos compreendem o discurso do professor de matemática. Há outras formas intermediárias de compreensão entre a compreensão passiva e a compreensão ativa plena. O ouvinte pode obter uma compreensão intermediária do que foi dito por seu interlocutor, ou seja, o ouvinte pode ter entendido o significado do signo linguístico, mas não ter obtido uma compreensão plena e em profundidade do enunciado. Deste modo, definimos compreensão intermediária a todas as formas de compreensão que não sejam a compreensão passiva nem a compreensão ativa plena. Em outros termos, neste estudo consideramos uma compreensão intermediária quando o aluno compreende aspectos de um discurso e deixa de compreender outros.

\section{Estudo do discurso e das interações na sala de aula}

Algumas pesquisas estão preocupadas com o discurso do professor no sentido de caracterizá-lo a partir da maneira como a linguagem é utilizada em sala de aula, ou seja, busca-se investigar os padrões de discurso adotado pelo professor no desenvolvimento de seu fazer pedagógico. Nessa perspectiva, destacam-se os trabalhos de Pimm (2004) e Monteiro (2002).

Revisar ou alterar os padrões de comunicação, ou mesmo buscar formas de comunicação apropriadas na sala de aula, é algo desejável na educação matemática. Entretanto, é preciso considerar que na sala de aula existe uma relação já consolidada que legitima o discurso do professor.

As interações discursivas são consideradas essenciais na sala de aula de matemática por diversos autores (SHOENFELD, 1989; DAVIDSON, 1990; COBB, 1999; FORMAN, 2003; CARVALHO, 2009). Além disso, devem ser entendidas na sua relação com contextos histórico-sociais e com as ferramentas culturais disponíveis para uma comunidade. As interações entre professor e alunos e entre os próprios alunos, dependendo das situações como ocorram, podem favorecer a compreensão do discurso do professor pelos alunos.

Considerando os estudos empíricos sobre o discurso, dedico uma maior atenção aos que abrangem, como objetivo principal, analisar as interações ocorridas no espaço social da sala de aula de matemática.

Innes (2007) fez um estudo em que analisou a qualidade do discurso na aprendizagem $^{4}$. $\mathrm{O}$ estudo constatou uma baixa incidência de diálogo de alta

\footnotetext{
${ }^{4}$ Neste estudo consideramos aprendizagem como a perspectiva que visa inserir indivíduos ou grupos de indivíduos em determinada cultura, e que para isto é necessário que o aprendiz atribua um significado ao que deseja aprender. Entendemos o termo significado como o que as coisas querem dizer em cada contexto, o que elas significam, o sentido do enunciado em cada situação.
} 
qualidade, em termos de comunicação dialógica, elaboração e construção de ideias em sala de aula pelos alunos. O pesquisador, que utiliza a palavra diálogo diferente do proposto por Bakhtin, apontou em seus estudos a necessidade de futuras investigações centradas nos aspectos socioculturais da aprendizagem para responder a questões da seguinte ordem: quais as ligações diretas e indiretas entre a qualidade dos diálogos em sala de aula e a qualidade da aprendizagem? Como os diálogos em sala de aula se relacionam com outras formas de discurso?

Diante da questão, "a noção de discurso só tem sentido no contexto de interação social, falando de discurso, em vez de conhecimento, exclui a possibilidade de ver a aprendizagem como um esforço puramente individual" (SFARD, 2000, p. 162). Além disso, conceitua o pensamento como uma instância da atividade discursiva. Na verdade, a natureza discursiva de conhecimento e aprendizagem torna claro que demandas de comunicação são a principal força por trás das atividades intelectuais e humanas e, assim, essas atividades são de natureza social, quer sejam realizadas individualmente ou em equipe. Finalmente, segundo a autora, a palavra discurso pode ser mais compreensiva que a palavra conhecimento.

Em uma pesquisa na qual analisam a forma como os professores organizam os estudantes para a participação dentro de suas atividades, que não abrangem apenas as ações de sala de aula e as interações não apenas matemáticas, Walshaw e Anthony (2006) exploram quais são as influências da participação dos alunos na sala de aula, por meio das interações.

Afirmam esses estudiosos que na Nova Zelândia a orientação para o trabalho em grupo com os alunos tem sido prescrita como uma questão central para o desenvolvimento pedagógico. No entanto, a evidência da pesquisa revela que as qualidades do agrupamento são construídas sobre o conhecimento das características de diferentes tipos de grupo e acompanhamento constante à procura de abrangência e eficácia para o grupo de alunos.

Ao fazer uma análise discursiva sobre a ambiguidade do discurso na sala de aula de matemática, Barwel (2003) afirma que, a partir dessa perspectiva, em vez de examinar se os alunos ou professores usam um termo matemático de forma correta ou não, de acordo com sua definição, o interesse está em como os participantes usam tais termos e o que eles fazem para usar. Então, as interações em sala de aula de matemática devem ser examinadas em função das práticas discursivas dos participantes.

Barwel (2003) conclui que a ambiguidade desempenha um papel na aprendizagem. Embora, popularmente, a matemática possa ser vista como 
essencialmente clara, a exploração do discurso matemático, estimulado pela dimensão transcrita sugere que este não é o caso. A ambiguidade faz um importante recurso discursivo no discurso da matemática escolar, e, talvez, em todo o discurso da matemática.

Desse modo, ao considerar o papel da ambiguidade na interação em sala de aula de matemática, o objetivo é compreender como a ambiguidade surge para os participantes, como eles lidam com ela e o que fazem em relação à matemática e ao trabalho de discussão.

Não há como separar o discurso em uma sala de aula da forma como ocorre a comunicação em geral, como diz Sfard (2000), embora a comunidade matemática crie diferentes composições de discursos. Entendemos que os professores sentem dificuldades de formular um discurso, de criar situações de interações discursivas que favoreçam a compreensão pelos alunos, e não é porque eles não queiram ou não tentem formular um discurso compreensível. E, nessa busca, terminam realizando um discurso ambíguo, que dificulta a compreensão pelos alunos.

Quanto à questão da ambiguidade, diz Bakhtin (2003, p. 274) “a indefinição terminológica e a confusão em um ponto metodológico central no pensamento linguístico são o resultado do desconhecimento da real unidade da comunicação discursiva - o enunciado". A existência do discurso está condicionada na forma de enunciações concretas dos falantes, sujeitos do discurso. O discurso é baseado na forma de enunciado pertencente a um determinado sujeito do discurso. Compreender detalhes do enunciado como unidade da comunicação discursiva permite compreender o discurso. O ouvinte, quando percebe e compreende o significado linguístico do discurso, ocupa em relação a ele uma posição que indica compreensão, concorda ou discorda com o que foi dito.

Martin, Towers e Pirie (2006) investigam sobre a possibilidade e a natureza da compreensão matemática coletiva. Ao referirem-se à compreensão matemática coletiva, apontam para os tipos de compreensão e aprendizagem quando um grupo de alunos trabalha, juntos, envolvidos com a matemática. Caracterizam o crescimento da compreensão coletiva da matemática como um processo criativo e emergente de improvisação e ilustram como isso pode ser observado em ação. Também, discutem como considerar o crescimento do conhecimento matemático como um processo coletivo que tem implicações para a prática de sala de aula e, em particular para a definição de tarefas matemáticas. Observam a compreensão coletiva como um fenômeno que está ligado ao contexto social do ambiente de aprendizagem e, não apenas na descrição das ações individuais dos alunos. 
Esses autores afirmam que "temos de reconhecer claramente as contribuições matemáticas das ações individuais, mas o crescimento do conhecimento matemático pode ser observado surgir no nível coletivo" (MARTIN; TOWERS; PIRIE, 2006, p. 180). Sugerem, com isso, prestar atenção ao que fazem os estudantes em suas improvisações em matemática e não apenas nos resultados.

Pesquisadores apontam resultados diferentes em relação às interações em sala de aula. Por exemplo, Vaccari (2007) e Martin, Towers e Pirie (2006) afirmam como se as interações fossem algo definitivo para a caracterização da aprendizagem, isto é, bastaria que ocorressem as interações e estaria assegurada a aprendizagem. Diferente disso, Sfard (2001) e Watson e Chik (2001) apresentam resultados que mostram não ser suficiente ocorrerem interações para garantir a aprendizagem.

Segundo esse prisma, vimos vários autores afirmarem que os diálogos em sala de aula promovem formas de interação que implicam em mudanças no desenvolvimento dos alunos. No entanto, isso não ocorre em todas as situações de interação, então, quais situações de interação são favoráveis para essas mudanças, ou dito de outro modo, quais situações de interação favorecem a compreensão do discurso do professor pelos alunos?

\section{Aspectos metodológicos}

Neste estudo, utilizamos uma abordagem qualitativa. A fonte de dados tem origem em observações registradas por meio de videogravações de aulas em uma turma do $6^{\circ}$ ano do ensino fundamental de uma escola pública. Quando da gravação das aulas, tomamos alguns cuidados sugeridos por Carvalho (2007). Seguimos as orientações dadas por essa autora, buscando realizar o planejamento, a gravação da aula completa e de uma sequência de aulas.

No momento das gravações, buscamos captar os momentos discursivos da professora e dos alunos, mas o foco se localizou nas interações e diálogos produzidos pela professora com seus alunos.

Após a gravação das aulas, selecionamos o que denominamos episódios de ensino, isto é, "momentos extraídos de uma aula, em que fica evidente uma situação que queremos investigar" (CARVALHO, 2007, p. 33). São recortes tomados, ou seja, momentos extraídos das aulas que consideramos significativos ou que evidenciaram uma situação pertinente ao objeto desta investigação.

Os interlocutores desta pesquisa foram uma professora, de nome fictício 
Carla, e os seus alunos de uma turma do $6^{\circ}$ ano do ensino fundamental. Mas, em particular, focamos o olhar em três alunos da turma de 18 alunos para os quais estamos estabelecendo, aqui, os nomes fictícios de João, Ricardo e Marta, que sempre sentam próximos, e quando dos trabalhos realizados em grupo participaram sempre do mesmo grupo. A delimitação aqui estabelecida visa buscar profundidade na compreensão.

O foco das filmagens foi localizado, de modo especial, sobre a professora Carla e o grupo de alunos: João, Ricardo e Marta. Neste estudo, na análise dos dados, quando é feita a referência a qualquer aluno externo ao grupo focalizado (João, Ricardo e Marta), utilizamos sempre a denominação aluno, pois, na maioria das vezes, não foi possível relacionar a voz do áudio com o aluno que falava, quando este não era João, Ricardo ou Marta. Foram gravadas 15 aulas em vídeo.

A professora Carla é experiente, tem 20 anos de atuação no magistério. Cursou Licenciatura Plena em Matemática na Universidade Estadual da Paraíba, é pós-graduada em Educação Matemática Básica. A professora Carla foi sempre solícita com os pesquisadores, indicando os três alunos que fariam parte da pesquisa. Para essa indicação, foi solicitado que ela não utilizasse como critério de escolha alunos que tivessem melhor desempenho em matemática. Solicitamos, ainda, que os alunos escolhidos sentassem próximos. Assim, a professora convidou dois alunos que, naturalmente, já sentavam próximos e convidou Marta para mudar do lugar que sentava de costume e sentar próximo a João e Ricardo. Dessa forma, as gravações em vídeo seriam facilitadas. A professora Carla e os alunos João, Ricardo e Marta também concordaram em participar do mesmo grupo quando da realização de atividades em conjunto.

Os alunos participantes da pesquisa residem em becos ou favelas muito próximos à escola e têm pouco acesso à cultura escolar. Segundo levantamentos da direção da escola, em torno de $60 \%$ dos alunos são filhos de pais analfabetos ou semi-analfabetos.

\section{0 encontro com a sala de aula}

Os episódios foram extraídos das 15 aulas gravadas em vídeo, ministradas pela professora Carla para ensinar o conteúdo de Ângulo em uma escola pública municipal da cidade de Campina Grande, estado da Paraíba. Em todas as aulas, a professora utilizou o livro texto adotado pela escola (IEZZI; DOLCE; MACHADO, 2005). 
A professora exigia que cada aluno utilizasse o próprio livro na sala de aula. Em suas aulas, a professora Carla dividia o tempo de cada aula em partes mais ou menos iguais entre a exposição diante do quadro-de-giz e a orientação aos alunos quando resolviam atividades propostas pelo livro texto. Essas atividades sempre eram realizadas em grupos de dois ou três alunos.

\subsection{Episódio 1}

Neste primeiro episódio, analisamos as interações entre a professora Carla e os alunos, no momento em que ela inicia a sua primeira aula sobre ângulos.

Professora: Ângulo: alguém sabe o que é um ângulo?

Aluno: Ângulos...

Professora: Alguém já viu?

Aluno: Triângulo.

Professora: Triângulo é uma coisa, ângulo é outra.

Marta: Eu sei aqui professora, vem cá, vem cá.

Professora: Não, vamos dizer, quem sabe assim dar uma ideia do que é um ângulo?

Aluno: É uma bola assim (ele faz um gesto com os dedos polegar e indicador das duas mãos, que simbolizam o formato de uma bola).

João: Assim professora (movendo a caneta faz um gesto indicativo no ar que representa um ângulo).

Ricardo: É um retângulo, um pritângulo.

Professora: Um ângulo é a região do plano limitada por duas semirretas que têm a mesma origem (escreve no quadro esta definição).

Aluno: Aí tem outra.

Professora: Isso aqui é um ângulo (mostrando a representação geométrica na lousa).

Marta: Eu não sabia não.

Professora: Depende da abertura do ângulo, aí ele pode ficar maior.

João: Tipo aquele negócio do relógio, num é professora?

Professora: Isso, os ponteiros do relógio. O que meu amor? Esses dois traços?

Aluno: Esse traço ali de baixo? (se referia ao símbolo utilizado entre as duas semirretas que formam o ângulo).

Professora: Esses dois traços?

Aluno: Sim. 
Professora: Isso representa o ângulo. Agora, na sala, vamos dar exemplos de mais ângulos, aqui dentro da nossa sala o que é um ângulo?

Marta: Isso aqui da cadeira (mostrando uma parte onde se localizava um ângulo de $90^{\circ}$.

Ricardo: A correia da sandália professora.

João: Professora esse negócio assim, esse negócio assim do quadro (João apontava para o canto do quadro, que representava um ângulo reto).

Professora: Tudo isso que vocês mostraram são exemplos de ângulos.

Observa-se que a professora Carla iniciou, indagando os alunos: "alguém sabe o que é um ângulo?" Os alunos começaram a apresentar o que sabiam sobre ângulo, ao responder a pergunta da professora: "é uma bola assim". Depois desses diálogos da professora com os alunos, que propiciou o gesto de um aluno, movimentando a caneta no espaço, indicando a forma de um ângulo, a professora apresentou a definição ou o conceito elementar de ângulo que o livro texto apresenta: "ângulo é a região do plano limitada por duas semirretas que têm a mesma origem". E, logo a seguir, pediu aos alunos que apontassem, na sala de aula, onde houvesse representação de um ângulo. Assim, a professora Carla utilizou, sequencialmente, as seguintes estratégias para ensinar ângulo a seus alunos: primeiro, indagações aos alunos, se eles sabiam o que era um ângulo e aguardou os alunos se pronunciarem; segundo, a definição matemática de ângulo e, em seguida, induziu seus alunos a buscar ao redor deles objetos que contivessem elementos representativos da forma geométrica de um ângulo, ou seja, a professora mobilizou os alunos para procurar dentro da própria sala de aula a identificação geométrica de ângulos. Essa mobilização dos alunos pela professora Carla, por buscar na sala de aula objetos que em sua configuração apresentassem algum elemento que representasse um ângulo, aponta que ela tinha o objetivo de encontrar caminhos que ajudassem na compreensão dos alunos sobre ângulo.

Entendemos que, desse modo, a professora Carla mobilizou três estratégias de ensino. A última etapa da sequência de ensino de ângulo foi a identificação, pelos alunos, de modo prático no ambiente físico onde se encontravam, de elementos que representassem um ângulo. Os alunos realizam essa atividade com desenvoltura e participam das interações discursivas nas três etapas de ensino mobilizadas pela professora, de duas maneiras: respondendo 
indagações da professora e perguntando.

Os alunos ocupam uma posição responsiva em relação ao discurso da professora Carla e respondem o que é ângulo. Ricardo mostra seus conhecimentos de geometria; para ele, ângulo "é um retângulo, um pritângulo" (o que será um pritângulo, para Ricardo?). Vários alunos se posicionam respondendo o que é um ângulo. Segundo Bakhtin (2003), na comunicação discursiva o ouvinte, quando compreende o significado linguístico do discurso:

[...] concorda ou discorda dele (total ou parcialmente), completa-o, aplica-o, prepara-se para usá-lo, etc.; essa posição responsiva do ouvinte se forma ao longo de todo o processo de audição e compreensão desde o seu início, às vezes, literalmente a partir da primeira palavra do ouvinte (BAKHTIN, 2003, p. 271).

Tomando-se por base as palavras de Bakhtin, entendemos que os alunos ocupam uma posição responsiva em relação ao discurso realizado pela professora.

Pelo observado na fala dos alunos, o que melhor expressa a compreensão sobre ângulo, isto é, a compreensão do discurso da professora Carla é o modo objetivo como eles identificam, nos objetos localizados na sala de aula, a representação de um ângulo. O discurso dos alunos, identificando ângulos nos objetos encontrados na sala de aula, ocorreu após o discurso da professora sobre o conceito de ângulo apresentado aos alunos na aula.

\subsection{Episódio 2}

O episódio abaixo foi extraído de um momento da aula em que a professora Carla explicava uma atividade que solicitara para que os alunos realizassem, envolvendo conhecimentos sobre os tipos de ângulos.

Professora: O começo do ângulo.

João: Olha.

Professora: Oh, eu quero saber (incompreensível). Então é o começo do vértice. $\mathrm{O}$ vértice não está aqui. Aqui é o lado. É aqui. É como se eu tivesse uma reta fechada, entendeu? Aqui é uma reta, aí eu fecho a reta, então meu meio é esse, então meus lados são esses dois.

Ricardo: Esse com esse, e esse com esse (nesse momento, a professora analisava com os alunos uma situação de duas retas concorrentes, buscando identificar os tipos de ângulos formados). 
Marta: Quando você trabalha com esse ângulo você faz de conta que não existe esse pedaço da reta, certo? (Marta se referia as semirretas opostas ao ângulo que ela analisava). João: Aí faz esse com esse e esse com esse (apontando para os segmentos de reta $\mathrm{OF}$ e $\mathrm{OE}$ ).

Marta: Isso mesmo.

João: Então, OF e OE formam um ângulo obtuso.

Ricardo: $\mathrm{E} \mathrm{OG}$ e $\mathrm{OH}$ formam um ângulo agudo.

Professora: Muito bem, está certo. E OF e OG formam que tipo de ângulo?

Marta: Ângulo agudo.

Ao fazer referência ao "começo do ângulo" ou a "reta fechada" entendemos que a professora apresenta um discurso que relativiza o rigor da linguagem matemática. Esse fato aponta uma tentativa da professora Carla de falar uma linguagem que favoreça a compreensão dos alunos. Utilizando essa linguagem, o seu discurso se tornaria mais acessível aos alunos. Afinal, onde fica o "começo de um ângulo"? Como se "fecha uma reta"? Podemos afirmar que essa é uma tentativa ou mesmo um modo de favorecer uma situação que, no entendimento da professora Carla, contribuiria para a compreensão por parte dos alunos, e que o episódio acima mostra ter acontecido.

Reconhecemos que não somente os alunos encontram dificuldades quando precisam fazer representações matemáticas. Dificuldades também são encontradas pelos professores e até pelos matemáticos, o que talvez explique o discurso matemático da professora.

D’Amore (2007) afirma que a matemática, mais que possuir uma linguagem específica, ela é uma linguagem específica e, nesse sentido, "um dos objetivos principais de quem ensina é o de fazer com que os alunos aprendam, não apenas entendam, mas também de que se apropriem dessa linguagem especializada" (D’AMORE, 2007, p. 249). Esse autor considera que a comunicação em sala de aula não ocorre na linguagem matemática dos matemáticos, mas também não ocorre na língua materna, é assumida uma sintaxe específica, uma semântica considerada oportuna e nasce uma língua estranha.

Por sua vez, os alunos em suas afirmações apresentam enunciados que estão marcados pelos enunciados tanto dos colegas quanto da professora. Por exemplo, na afirmação de Marta, "Quando você trabalha com esse ângulo você faz de conta que não existe esse pedaço da reta, certo?”.

Bakhtin (2003) afirma que o enunciado sempre se encontra repleto de 
ecos das vozes alheias, pelo fato de um modo ou de outro ser marcado pela alternância dos sujeitos. Em cada enunciado, as interações ocorrem pelo contato, "no campo de quase todo enunciado uma interação tensa e um conflito entre sua palavra e a de outrem" (BAKHTIN, 1988, p. 153). Na perspectiva de Bakhtin, cada enunciado é um elo na cadeia discursiva e nenhum deles é independente, solitário. Isto pode ser observado nos diálogos e nas interações ocorridas entre os alunos, na atividade realizada na sala de aula da professora Carla.

\subsection{Episódio 3}

No trecho a seguir, a professora Carla ensina medida de ângulo em uma circunferência.

Professora: Observe a comparação, a circunferência toda é $360^{\circ} .180^{\circ}$ é aqui no 6 . Se chegar aqui no 3 , quantos graus é? João: 380 graus.

Professora: Não. Observe $180^{\circ}$ é aqui no 6, compare, quando chegar no 3, é quanto?

Aluno: 30 graus.

Marta: 90 graus.

Professora: 90 graus. Se a metade foi $180^{\circ}$, a metade de $180^{\circ}$ é $90^{\circ}$, olha então aqui fica a metade. Então, comparando um relógio com essa figura quando a gente conta cada tracinho desse é 30 graus. Aqui eu tenho 60 graus. Aqui eu tenho 90, 120, 150, 180, certo? Então, quanto mede esse ângulo?

Aluno: 240 graus.

Professora: Exato.

Professora: E este ângulo quanto mede?

Ricardo: 270 graus.

Professora: E este ângulo aqui mede quanto?

Maria: 300 graus.

Professora: Aqui eu dou a volta completa que é quanto?

Aluno: 360 graus.

Professora: Então vamos aqui, esse ângulo aqui mede quantos graus?

Aluno: 8 graus.

Professora: Quantos graus mede esse ângulo?

João: 90 graus.

Professora: Eu mostrei assim, a gente fez assim.

Marta: 90 graus.

Professora: Então esse ângulo aqui ele mede $90^{\circ}$. Esse 
ângulo aqui de $90^{\circ}$ ele parece com o que na sala que a gente mostrou?

João: Com a cerâmica. Com a ponta do quadro.

Os alunos estão dialogando com a professora, estão sempre com uma resposta para apresentar. No trecho inicial, quando os alunos não apresentaram a resposta esperada pela professora, ela não respondeu de imediato, mas aguardou que eles descobrissem a resposta.

A compreensão é considerada por Bakhtin (2006) um processo de interação, como o que ocorreu no trecho da aula que acabamos de apresentar, para ele a compreensão tem uma natureza responsiva e "toda compreensão é prenhe de resposta, e nessa ou naquela forma a gera obrigatoriamente: o ouvinte se torna falante" (BAKHTIN, 2003, p. 271). Um elemento marcante da compreensão é a resposta, isto é, a interação verbal.

As interações dos alunos com a professora Carla estão recheadas de respostas breves e curtas, mas dentro das circunstâncias da atividade desenvolvida em sala de aula. Aqui se apresenta uma situação na qual a compreensão dos alunos se caracteriza, nos termos em que definimos, por uma compreensão intermediária. Observe que João e um dos alunos respondem $380^{\circ}$ e $30^{\circ}$, respectivamente, quando a resposta seria $90^{\circ}$; depois outro aluno responde $8^{\circ}$, quando a resposta esperada também seria $90^{\circ}$. Entretanto, na sequência das interações João parece ter evoluído em sua compreensão ao responder da forma esperada a pergunta da professora, e, junto a outros alunos, mostra uma orientação em relação aos enunciados da professora, ao que é perguntado (BAKHTIN, 2006), e as respostas apresentadas por eles se localizam no contexto.

\section{Discussão}

Como vimos, compreender está relacionado com a produção de palavras, com a resposta sobre o que foi enunciado pelo interlocutor. É possível afirmar que na sala de aula da professora Carla ocorreu a alternância de momentos de interações mais intensos entre a professora e os alunos e entre os próprios alunos, com momentos de pouca interação. Foi possível verificar que houve situações em que ocorreu uma modificação na construção matemática dos alunos durante as interações, essa modificação parece ter ocorrido no sentido de uma modificação da sua compreensão acerca do discurso da professora.

No episódio 1 observam-se trechos em que o discurso da professora 
Carla relaciona a explicação do conteúdo de ângulo que estava ensinando a situação do dia-a-dia. Por exemplo, quando João afirma, "tipo aquele negócio do relógio, num é professora?", e a professora responde, "isso, os ponteiros do relógio". Ou quando a professora Carla afirmou, "agora, na sala, vamos dar exemplos de mais ângulos, aqui dentro da nossa sala o que é um ângulo?”. Logo em seguida, os alunos Marta, Ricardo e João encontraram palavras para responder à professora. Entendemos que, aqui, se apresentam situações nas quais a professora busca favorecer a compreensão de seu discurso, obtendo dos alunos posicionamentos que indicam compreensão, isto é, os alunos apresentam respostas ao discurso da professora, fazem réplicas ao discurso da professora (BAKHTIN, 2006). Ao pautar seu discurso na relação do discurso matemático com situações do dia-a-dia a professora pode desenvolver outro olhar para a sala de aula como espaço institucional de produção de conhecimento. Isso permite ouvir os discursos dos alunos, procurar entender de onde eles partem, como relacionam informações e conhecimentos e como justificam ou explicam essas relações e que suposições ou hipóteses elaboram.

O discurso da professora Carla no episódio 2 relativiza o rigor da linguagem matemática, forma que ela encontrou para tornar o seu discurso compreensível aos alunos. Isso pode ser observado na reação dos alunos ao discurso da professora. É importante não ignorar o tipo de comunicação que acontece nas aulas de matemática, pois este constitui um indicador da natureza do processo de ensino e aprendizagem (NACARATO; MENGALI; PASSOS, 2009). O discurso realizado, relativizando o rigor da linguagem matemática traz implicações. Para D'Amore (2007) isso evidencia um paradoxo da linguagem específica. Para esse autor, o ensino é comunicação e um de seus objetivos é o de favorecer a aprendizagem dos alunos, então, quem comunica deve fazê-lo de um modo que a linguagem utilizada não seja uma fonte de obstáculos à compreensão dos alunos. Por outro lado, "a matemática possui uma linguagem específica (ou até mesmo é uma linguagem específica)” (D’AMORE, 2007, p. 249). Então, fica um desafio ao professor, utilizar uma linguagem que favoreça a compreensão dos alunos e, ao mesmo tempo, não descuidar da linguagem específica da matemática que os alunos devem aprender.

Na situação observada, entendemos que é possível, em determinado momento, utilizar uma linguagem que relativize o rigor da linguagem matemática, mas que também não signifique descuidar da sua linguagem específica e necessária de ser ensinada. A relativização momentânea do rigor da linguagem matemática pela professora foi uma forma encontrada para contribuir para a 
compreensão pelos alunos do que está sendo dito por ela.

Já no episódio 3, a professora Carla faz um discurso no qual ensina o conteúdo envolvendo comparações de proporcionalidae. Ao mostrar o desenho de um relógio e indicar que às 6 horas os ponteiros de um relógio formam um ângulo de $180^{\circ}$, então, às 3 horas formaria um ângulo de $90^{\circ}$. É interessante observar que o discurso comparativo que a professora fez, levou os alunos a realizarem comparações também, eles passaram a identificar ao redor deles, na sala de aula, objetos que apresentavam um ângulo medindo $90^{\circ}$.

Considerando o instrumental bakhtiniano acerca do conceito de compreensão, a noção teórica de compreensão intermediária que apresentamos e os dados empíricos é possível propor o seguinte quadro resumo das situações ocorridas na sala de aula da professora Carla:

\begin{tabular}{|l|l|}
\hline Situação de interação & Compreensão dos alunos \\
\hline A professora faz relação do conteúdo com situações do dia-a-dia & Ativa plena \\
\hline A professora relativiza o rigor da linguagem matemática & Ativa plena \\
\hline $\begin{array}{l}\text { A professora ensina o conteúdo fazendo comparações entre objetos } \\
\text { matemáticos }\end{array}$ & Intermediária \\
\hline
\end{tabular}

Quadro 1 - Resumo das situações ocorridas na sala de aula.

Essas situações foram encontradas na sala de aula da professora Carla, com isso não é possível afirmar que tais situações possam ser extensivas a outras salas de aula. Por sua vez, a caracterização de uma situação apresentada como a ocorrência de uma compreensão intermediária, ou uma compreensão ativa plena, não pode ser tomada como uma medida, mas como indícios apresentados pelos dados empíricos e pelo quadro teórico utilizado.

\section{Considerações finais}

Este estudo analisou situações de interações discursivas na sala de aula de matemática que podem favorecer a compreensão do discurso do professor pelos alunos. Foram identificadas três situações de interações em que o gênero do discurso utilizado pela professora Carla aponta nessa direção.

Os resultados demonstram que tais situações dependem do gênero de discurso utilizado pela professora. Em três situações isso pôde ser observado. A primeira, quando o gênero do discurso da professora se referiu a situações encontradas na sala de aula. A segunda, quando a professora utilizou um gênero 
de discurso que relativiza o rigor da linguagem matemática. E a terceira, quando a professora tentou estabelecer comparações ou deduções. Na primeira situação entendemos que os alunos apresentam uma compreensão ativa plena e na segunda e terceira situações a compreensão dos alunos é característica do que denominei de compreensão intermediária.

Em geral, nas situações de interações ocorridas na sala de aula entre os próprios alunos foram situações que sinalizaram uma compreensão intermediária ou uma compreensão ativa plena pelos alunos. Esse resultado diverge dos resultados encontrados por Sfard e Kieran (2001), ao afirmarem que, em seus estudos, analisando as interações entre dois adolescentes elas foram ineficazes.

Como implicações deste estudo, o discurso do professor pode ser realizado de modo a contemplar múltiplos aspectos para favorecer a compreensão pelo aluno, seja guardando fidelidade ao discurso matemático formal, seja recorrendo a outros aspectos. O discurso do professor na sala de aula de matemática pode buscar conexão com situações do dia-a-dia, pode relativizar o rigor matemático em certas ocasiões, e pode recorrer a outros aspectos para favorecer a compreensão pelos alunos. Sendo assim, na sala de aula, o discurso do professor ocupa um lugar na comunicação discursiva que depende do tipo de relação que ele estabeleça com seus alunos e ainda, do modo como o professor organiza as situações pedagógicas de ensino na sala de aula de matemática.

\section{Referências}

BAKHTIN, M. Estética da criação verbal. 4. ed. São Paulo: Martins Fontes, 2003.

BAKHTIN, M. Marxismo e filosofia da linguagem. 12. ed. São Paulo: Hucitec, 2006.

BARWEL, R. Ambiguity in mathematics classroom discourse. Proceedings of the British Society for Research into Learning Mathematics, Manchester, v. 23, n.3, p. 1-7, Nov. 2003.

CARVALHO, A. M. P. Uma metodologia de pesquisa para estudar os processos de ensino e aprendizagem em salas de aula. In: SANTOS, F. M. T.; GRECA, I. M. (Orgs.). A pesquisa em ensino de ciências no Brasil e suas metodologias. Ijuí: Editora Unijuí, 2007.

CARVALHO, C. Comunicações e interações sociais nas aulas de matemática. In: LOPES, A. E.; NACARATO, A. M. (Orgs.). Escritas e leituras na educação matemática. Belo Horizonte: Autêntica, 2009. 
COBB, P. Individual and collective mathematical development: the case of statiscal data analysis. Mathematical Thinking and Learning, Philadelphia, USA, v.1, n. 2, p. 5-43, 1999.

DAVIDSON, N. Cooperative learning in mathematics. San Francisco: AddisonWesley, 1990.

D’AMORE, B. Elementos de didática da matemática. Tradução: Maria Cristina Bonomi. São Paulo: Editora Livraria de Física, 2007.

FLORES, V. do N. et al. Dicionário de linguística da enunciação. São Paulo: Contexto, 2009.

FORMAN, E. A. A sociocultural approach to mathematics reform: Speaking, inscribing, and doing mathematics within communities of practice. In: KILPATRICK, J.; MARTIN, W. G.; SCHIFTER D. (Eds.). A research companion to Principles and Standards for School Mathematics, Reston, VA: National Council of Teachers of Mathematics, 2003. p. 333-352.

INNES, R. B. Dialogic communication in collaborative problem solving groups. International Journal for the Scholarship of Teaching and Learning, Indiana, v. 1, n. 1, p. 1 -19, Jan., 2007.

IEZZI, G.; DOLCE, O.; MACHADO, A. Matemática e realidade - $5^{\mathrm{a}}$ série do ensino fundamental. 5. ed. São Paulo: Atual, 2005.

MARTIN, L.; TOWERS, J.; PIRIE, S. Collective mathematical understanding as improvisation. Mathematical Thinking and Learning, Philadelphia, USA, v. 8, n. 2, p. 149-183, 2006.

MONTEIRO, M. A. A. Interações dialógicas em aulas de ciências nas séries iniciais: um estudo do discurso do professor e as argumentações construídas pelos alunos. 2002. 187f. Dissertação (Mestrado em Educação Ensino de Ciências) - Faculdade de Ciências, Universidade Estadual Paulista, Bauru, 2002.

NACARATO, A. M.; MENGALI, B. L. da S.; PASSOS, C. L. B. A matemática nos anos iniciais do ensino fundamental: tecendo fios do ensinar do aprender. Belo Horizonte: Autêntica, 2009. Coleção Tendências em Educação Matemática.

PIMM, D. Discourse analysis and mathematics education: an anniversary of sorts. In: INTERNATIONAL CONGRESS ON MATHEMATICAL EDUCATION, 26 ${ }^{\text {th }}, 2004$, Copenhagen. Proceedings... Copenhagen: Douglas E. Macdougall e Jhon A. Ross, 2004. 
SCHOENFELD, A. Ideas in the air: speculations on small group learning, environmental and cultural influences on cognition, and epistemology. International Journal for Research in Mathematics Education, California, v.13, n.1, p.71-78, 1989.

SFARD, A. On reform movement and the limits of mathematical discourse.

Mathematical Thinking and Learning, Philadelphia, USA, v.2, n.3, p.157-189, 2000.

SFARD, A. Learning mathematics as developing a discourse. In: CONFERENCE OF PME-NA, $21^{\text {Th }}$, 2001. Columbus/Ohio. Proceedings... Columbus/Ohio, USA: R. Speiser, C. Maher, C. Walter (Eds), p. 23 - 44.

SFARD, A.; KIERAN, C. Cognition as communication: rethinking learning-by-talking through multi-faceted analysis of students mathematical interactions. Mind, Culture, and Activity. United Kingdom: Routledge, v. 8, n.1, p.42-76, 2001.

VACCARI, B. V. A interação na sala de aula de matemática. Depositada em 2007. $147 f$. Dissertação (Mestrado em Ensino de Ciências e Matemática), ULBRA - Universidade Luterana do Brasil, Porto Alegre, 2007.

WATSON, J. M.; CHICK, H. L. Factors influencing the outcomes of collaborative mathematical problem solving: an introduction. Mathematical Thinking and Learning, Philadelphia, USA, v. 3, n. 2/3, p.125-173, 2001.

WALSHAW, M.; ANTHONY, G. Classroom arrangements that benefit students. 2006. Disponível em: <http://www.merga.net.au/documents/RP612006.pdf> Acesso em: 10 set. 2009. 